\title{
Research on Price Adjustment of Construction Contract Caused by Force Majeure
}

\author{
Ke Zhao \\ Department of Industrial Engineering, Tianjin University of Technology, Tianjin, 300384, China \\ email: 2694933309@qq.com
}

Keywords: force majeure, Shapley value correction method, Price adjustment

\begin{abstract}
In construction projects, adjustment of contract price caused by force majeure often leads to disputes and disputes between the two parties, which in turn leads to uncontrolled investment in the project. Force majeure is one of the core factors affecting the price adjustment of construction contracts. The risk sharing of force majeure mainly abides by the principle of imputation ${ }^{[1]}$. However, this is only a qualitative study and is not conducive to engineering practice. Based on redefining the connotation of force majeure and building a bank of force majeure, this paper analyzes the research status quo of price adjustment mechanism of construction contract. In view of the lack of quantitative research, practical application, and poor guidance to engineering practice, this paper introduces the Shapley value correction method and constructs the contract price adjustment mechanism based on the Shapley value correction method. In this paper, a case of force majeure caused by the lifting of the contract, the analysis of the force majeure caused the contract to lift the way of study, and to relieve the contract after the release of responsibility for the study.
\end{abstract}

\section{Introduction}

The completion of a construction project to deal with possible problems and risks that may arise, some of which can be controlled, but more beyond its control. This type of natural disasters and social anomalies that can not be foreseen by the parties when signing a construction contract and are unavoidable or insurmountable for their losses are defined as "force majeure." Force majeure when the construction project has a devastating and devastating impact ${ }^{[2]}$; Second, the occurrence of force majeure not only with the loss of material, but also lead to more casualties; Finally, as the level of social science and technology continue Increase, more and more human beings can predict and overcome the force majeure matters, and some changes have taken place in the extension and connotation of the force majeure. These factors together lead to disputes over the adjustment of the contract price caused by the force majeure. In recent years, the project has gradually expanded the scale of production, the construction period has been gradually extended, the number of stakeholders has been gradually increased, the construction site has been fixed, and the consumption of materials and equipment has been gradually increasing. As a result, it has been affected by the environmental impact of nature and society the bigger it is. Therefore, the price adjustment of the construction contract triggered by the event of force majeure has now become an important issue in the field of construction engineering.

\section{The redefinition of the concept of force majeure}

\subsection{The redefinition of the meaning of force majeure}

Among the current laws and regulations in our country, the definition of "force majeure" is "General Principles of Civil Law", "Contract Law", "Code for Construction Engineering Quantities List" (GB 50500-2013), "Standard Construction Bidding Documents" (2007) ) And "Model Construction Contract for Construction Contract" (GF-2013-0201), as shown in the following table. The definitions of relevant laws, regulations and various types of contract templates fall into two categories, as shown in Table 1.1 below. 
Table 1. The Comparison of Laws and Contracts to the Connotation of the Force Majeure

\begin{tabular}{|c|c|c|c|c|c|}
\hline \multirow{2}{*}{ Type } & \multirow{2}{*}{ Laws and regulations } & \multirow{2}{*}{ provision } & \multicolumn{3}{|c|}{ Definition of force majeure } \\
\hline & & & \multicolumn{2}{|r|}{ Three can not } & Two properties \\
\hline \multirow{2}{*}{$\begin{array}{l}\text { Type } \\
\text { one }\end{array}$} & Civil Law & Article 153 & \multirow{2}{*}{\multicolumn{2}{|c|}{$\begin{array}{l}\text { Can not be foreseen, can not be avoided and } \\
\text { can not be overcome }\end{array}$}} & \multirow{2}{*}{ Objective case } \\
\hline & contract law & Article 117 & & & \\
\hline \multirow{3}{*}{$\begin{array}{l}\text { Type } \\
\text { two }\end{array}$} & $\begin{array}{l}13 \text { version of the } \\
\text { construction project } \\
\text { bill of quantities } \\
\text { pricing specification }\end{array}$ & 2.0 .27 & \multirow{3}{*}{$\begin{array}{l}\text { The contractor } \\
\text { and the } \\
\text { contractor can } \\
\text { not predict } \\
\text { when signing } \\
\text { the } \\
\text { construction } \\
\text { contract }\end{array}$} & $\begin{array}{l}\text { Its consequences can not } \\
\text { be avoided and can not be } \\
\text { overcome }\end{array}$ & \multirow{3}{*}{$\begin{array}{c}\text { Natural disasters } \\
\text { and social } \\
\text { emergencies }\end{array}$} \\
\hline & $\begin{array}{l}07 \text { version of the } \\
\text { standard construction } \\
\text { bidding documents }\end{array}$ & 21.1.1 & & $\begin{array}{c}\text { In the construction } \\
\text { process inevitable and can } \\
\text { not be overcome }\end{array}$ & \\
\hline & $\begin{array}{c}13 \text { version of the } \\
\text { construction project } \\
\text { construction contract } \\
\text { model text }\end{array}$ & 17.1 & & $\begin{array}{c}\text { It is inevitable and can not } \\
\text { be overcome in the } \\
\text { performance of the } \\
\text { contract }\end{array}$ & \\
\hline
\end{tabular}

Source: Draw on your own

It can be seen from the above analysis that regardless of the current legislative requirements of our country or other laws and regulations, the following four points must be adhered to when determining force majeure: objective events can not be foreseen, can not be avoided, and can not be overcome. Because the part of the controversy in the definition of the malady of force majeure has included the behavior of the government into the category of force majeure and because the government behavior is not a sudden event of the society, this study divides the event of force majeure into the events of natural and social force majeure, Government actions are classified as social force majeure events. Based on the subjective and objective elements of force majeure, unforeseen subjects and the unforeseen and unavoidable and insurmountable definitions, the definition of the force majeure extension in the field of construction engineering is redefined. The definition of force majeure in this research is defined as: If the contracting parties are totally unforeseeable or not completely foreseeable at the time when the construction contract is signed and at the existing level of science and technology during the performance of the contract, the nature of the contracting parties that can not be avoided and whose consequences can not be overcome completely or completely can not be overcome or Social events.

\subsection{The redefinition of the force majeure extension}

Firstly, it collects force majeure events from the laws, regulations and contract models in the field of construction engineering and the related literature on the scope and classification of the force majeure and initially builds the force majeure risk repositories; then screens the force majeure connotations redefined by the potential force majeure events in the preliminary risk repositories; Finally, the ultimate risk maneuver bank, and a detailed classification of them. According to literature review of force majeure extensibility, we can see that in the current laws and regulations documents and academic research, the events of force majeure are mainly divided into two categories: nature and society. This research builds the force majeure risk library from these two aspects. Natural force majeure events are the main components of force majeure and refer to the natural phenomena that can endanger human life or cause damage to human beings' living environment. Social-class force majeure refers to social anomalies (or social emergencies) that are caused by the political behavior of social groups and may cause serious harm to society such as war, terrorist attacks, military coup, riots and strikes These incidents are neither predictable nor to be avoided and overcome by the parties to the contract. The final bank of force majeure built in this study is shown in Figure 1.1 below: 


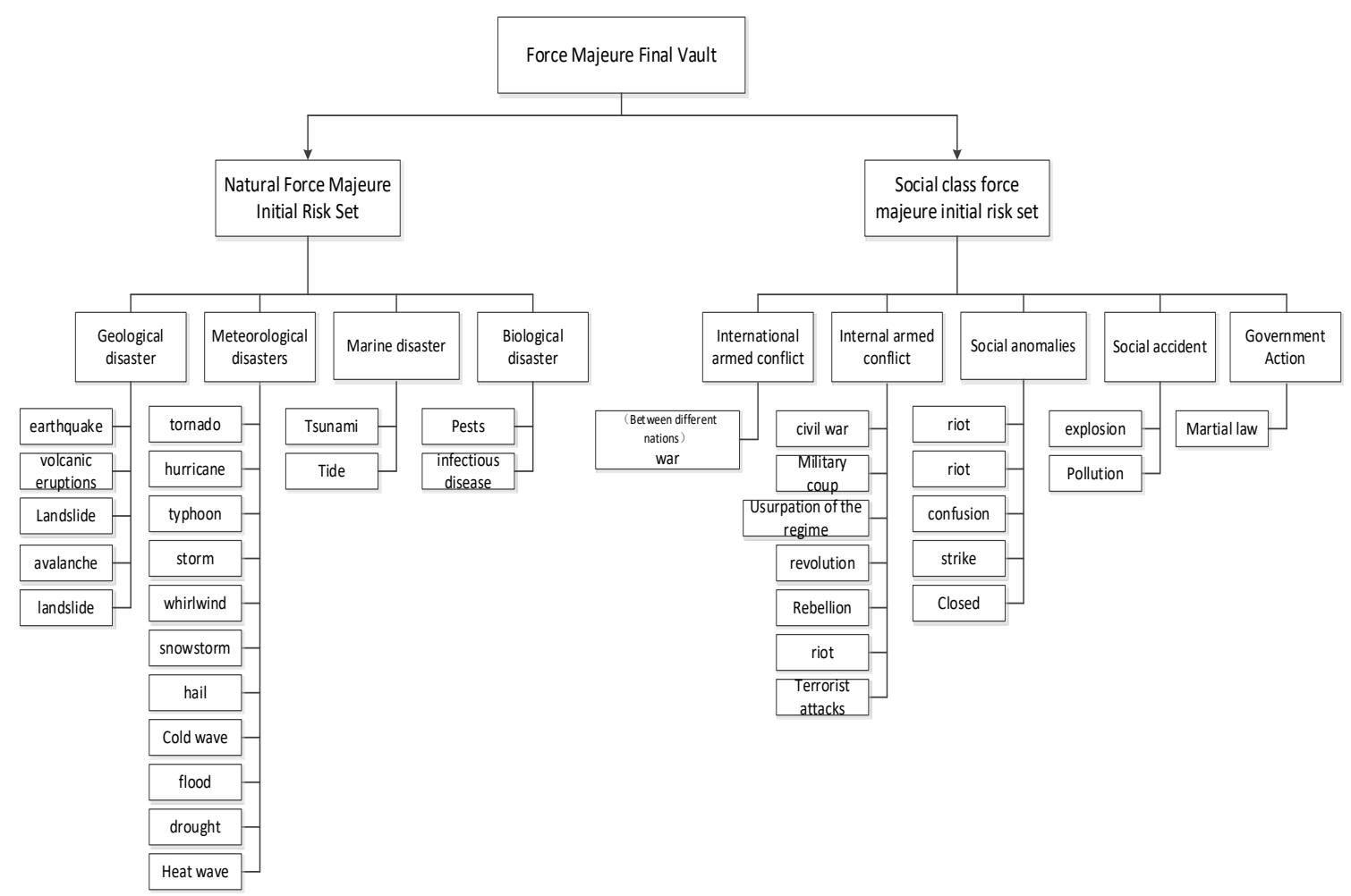

Fig.1 Finally Library of Force Majeure

Source: Draw on your own

\section{The contract price adjustment mechanism caused by the force majeure}

\subsection{Construction contract price adjustment mechanism}

After the occurrence of risk events, the choice of price adjustment methods has a crucial impact on whether construction contracts can be continued or not. Because, the contract price adjustment method and the contractor and the economic interests of the contractor are inseparable, and the entire project can continue to play a decisive role. The essence of the contract price adjustment caused by force majeure is the process of adjusting the dynamic redistribution of the losses caused by force majors and contractors, the distribution of losses after the occurrence of force majeure events and the risks involved in the implementation of the contract. And to ensure the contractor to provide the contractor with the best possible engineering construction service [3] on the basis of obtaining reasonable income, the loss caused by the force majeure shall be controlled within the reasonable range that each of the parties to the contract can bear.

Build a complete set of management system of project price, focusing on the way of adjusting the contract price caused by factors such as price changes and changes in laws and regulations, mainly reflected in engineering changes, two ways to adjust the contract price [4]. After the event of force majeure, the contract price generally needs to be adjusted accordingly, and the ways in which the contracting parties and the contractor adopt the method of adjusting the contract price can get the maximum overall benefit.

Project risk sharing and contract price adjustment process to qualitative description of the main lack of quantitative analysis. The adjustment models of construction contract price are: linear programming model, neural network model, fuzzy comprehensive evaluation model, etc. However, these methods are all focused on the theoretical research, and the actual project is not closely linked, it is difficult to apply to engineering practice. Through the above literature analysis, a lot of contract price adjustment methods used by Gao Hua, Qi Hao and other scholars Shapley value correction method is a quantitative and qualitative combination of practical project risk sharing method. In view of this, this study will use the Shapley value correction method to explore the construction contract price adjustment mechanism caused by force majeure. 


\subsection{The Applicability Analysis of Shapley Value Method in the Risk of Force Majeure of Construction Project}

When multiple parties work together on an economic activity, their cooperation obtains the maximum benefit when the gains they obtain in the activity are non-confrontational. The Shapley value method is a method to distribute such income. At present, Shapley value method is more and more widely used.

After the event of force majeure, participants can form various alliances in the cooperative game to allocate the resulting losses. The ultimate distribution of losses for each participant in the coalition is the Shapley value, which is defined as follows:

The Shapley value is the distribution of benefits (or cost-sharing) that each affiliate member receives in a cooperative game.

$$
\Phi=\left(\phi_{1}, \phi_{2}, \ldots, \phi_{N}\right) \text {, among them } \phi_{i}(N, v)=\sum_{\tau \subset N} \frac{(|\tau|-1) \cdot(N-|\tau|) !}{N !} m_{i}(\tau), \quad \phi_{i}(N, v) \text { is the Shapley }
$$

value of the cooperative game $(N, v)$.

$N$ : Participant Alliance, the construction project refers to both the contractor and the contractor of the alliance;

$v$ : The return function, which represents the expected loss of risk that the contracting parties can reduce after they form a coalition, indicates the expected loss of risk that the coalition can reduce after removing the participants.

$\tau$ : All kinds of alliances formed by the participants, that is, all kinds of alliances that the contractor and the contractor can form in the construction project mean the number in the alliance;

$m_{i}(\tau)$ : Participants' marginal contribution to the alliance, construction project means that the outsourcer or contractor's marginal contribution to the alliance, $m_{i}(\tau)=v(\tau)-v(\tau /\{i\}), i \in \tau$ 。

The Shapley value is generally used to study the distribution of benefits [5] [6], so as to make the benefits obtained by all parties more balanced and reasonable. However, the risks and benefits are also a pair of contradictory contradictions. Interests must be borne by certain risks. There is also the possibility of risks brought by risks. There is a clear symmetrical relationship between interest distribution and risk sharing.

\section{Establishment of risk-sharing model of force majeure based on Shapley value correction method}

The Shapley value method assumes that the participants are homogeneous and does not have individual characteristics, and thus can not reflect the respective capability differences between the two parties in terms of risk control and risk appetite. The modified Shapley value takes into account the differences among the participants and gives the corresponding proportion of the various factors by the AHP method. The Shapley value is corrected according to the proportion of the difference, so that the modified Shapley value More tend to perfect. Therefore, this study uses a modified Shapley value method to build a risk-sharing model of the force majeure, and then gives a brand-new contract price adjustment mechanism.

\section{1 model assumptions}

Hypothesis 1: The loss sharing of force majeure events in construction projects should follow five principles, namely the effective control principle, the principle of reciprocity of risk and return, the principle of risk preference and the principle of risk sharing in the relevant literature of domestic representative scholars in recent years Dynamic principle.

Hypothesis 2: The Employer and the Contractor comply with the hypothesis of the economists that they are risk averse. 


\section{2 model building}

Based on the above two assumptions, combined with the five factors that affect the risk-sharing of the construction project's force majeure, this study builds the irreducible risk-sharing model using the Shapley value correction method, as shown in Figure 1.2.

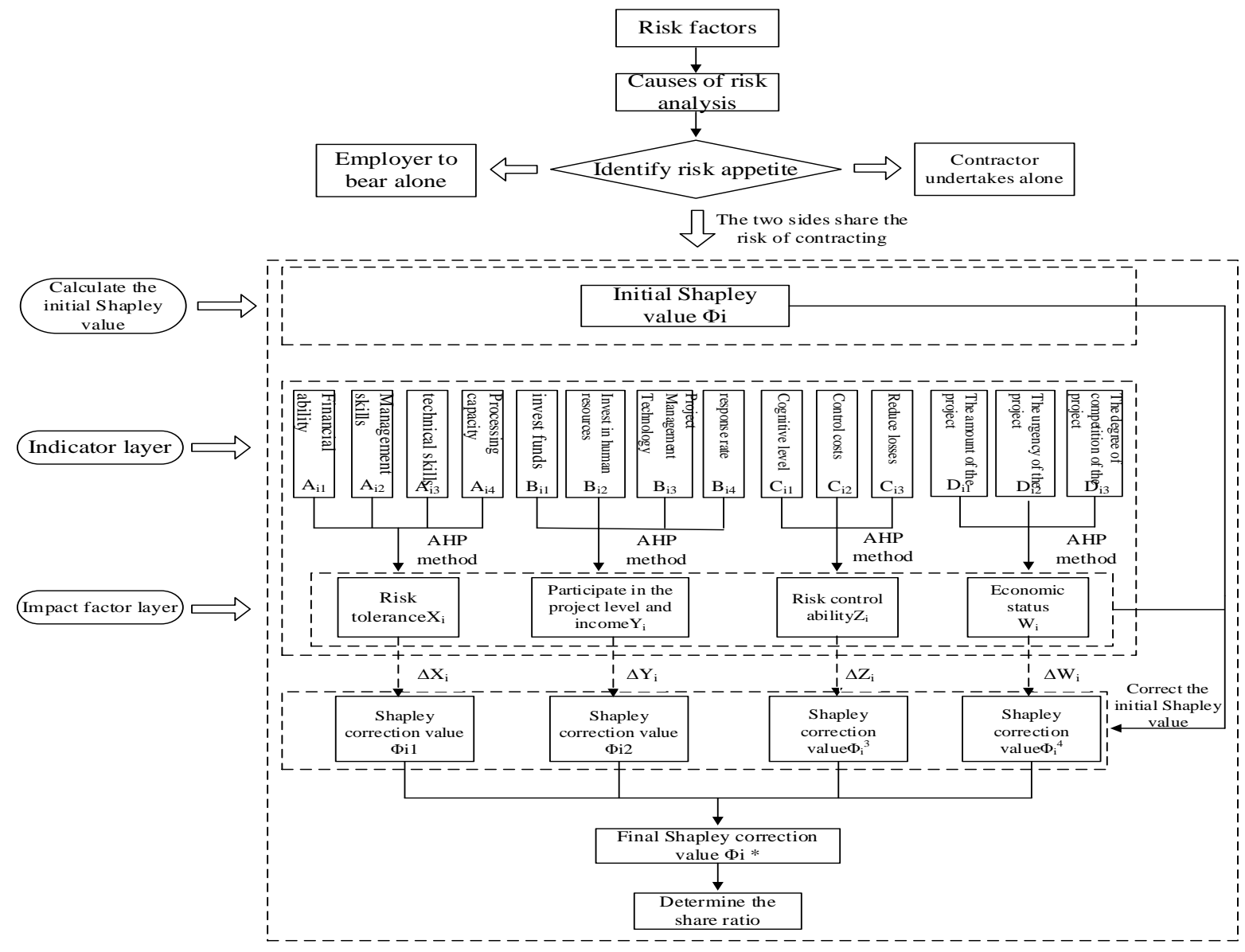

Fig.2. Force Majeure Risk Sharing Model Based on Improved Shapley Method

Source: Draw on your own

The model is divided into two parts:

The first part: Through the analysis of the cause of risk, identify the part of the risk should be borne by both parties to the contract, such risk by the Employer or the contractor to bear alone.

the second part: Identify the part of the risk that should be shared by both parties in the contract, using the Shapley Value Amendment method to calculate the share between the contractor and the contractor. This section is divided into four steps:

The first step is to calculate the initial Shapley value of the construction project risk majeure.

Without considering the differences among the participants in the project, the initial Shapley value that can be obtained for the risk sharing of the project's force majeure is $\phi_{i}(N, v)=\sum_{\tau \subset N} \frac{(|\tau|-1) !(N-|\tau|) !}{N !} m_{i}(\tau), i=12$

The second step, the experts conducted a questionnaire survey, the use of AHP method to obtain the risk factors of each of the weight of the risk factors and the weight of each indicator.

The third step, for different types of risk-sharing, and then by the experts given the contract each of the two indicators of the score, combined with the various indicators and the weight of the influencing factors to calculate the contractual weight of each risk-sharing influencing factors.

The fourth step, Shapley value correction. The initial Shapley value is modified by combining the weighted risk-influencing factors of both parties in the contract, then the modified Shapley value is weighted to obtain the final modified Shapley value of both parties, so as to determine the 
risk between the contractor and the contractor Share ratio.

\section{Force Majeure caused the contract to lift the exemption from the study}

In the event of an event of force majeure, three situations may arise: first, the contract can not be completely discharged if force majeure causes the contract to be lifted, and the lifting is statutory, and the party that automatically releases the contract and can not perform the contract at all In the case of force majeure, the part of the contract can not be fulfilled. In this case, whether the party that discharged the contract and the part in which the contract can not be performed has the right to exercise the contractual right of cancellation depends on the other party, which is an agreement The way the third force majeure event affects the contract is temporary. However, if the purpose of the contract is seriously affected after the delay, the parties should terminate the contract. In addition, the acts of force majeure resulting in the rescission of contracts often have the same devastating impact on the construction in progress as they may completely destroy the existing works or seriously damage the surrounding environment such as earthquakes, volcanic eruptions, tsunamis and wars.

The exemption of contract liability means that due to the provisions of the laws and regulations or the contract, part of the damages caused to the breach of contract shall be exempted or totally exempt from liability. In the exemption effect, the force majeure can only be exempted from the responsibility corresponding to its causal force [7]. The reason that force majeure is the most important type of alien cause defenses originates from the fact that force majeure is often regarded as a defense of negative causality. The damage results from external causes and there is no causal link between acts and damages and should not be undertaken Liability. Force majeure as a mandatory exemption shall not require the infringer to assume full responsibility. For example, in the FIDIC Red Book, the risk of force majeure is basically classified as a risk that should be borne solely by the Employer.

In construction projects, if due to force majeure events, whether it leads to the lifting of the contract, should first determine the situation belongs to the contract can not be fully implemented, the contract part of the performance can not be delayed and the performance of the contract; Second, to identify whether they meet with the release The conditions and the right to rescind the subject is correct; Finally, to determine whether the exclusion of liability is wholly or partially exempt.

\section{Conclusion}

First of all, this research redefines the connotation and denotation of the force majeure by literature review method and comparison of laws and regulations documents, on the basis of which it builds the force majeure risk repositories and reclassifies the risks in the library.

Secondly, on the basis of redefining the connotation of force majeure and constructing a bank of force majeure, the status quo of research on price adjustment mechanism of construction contract is analyzed. In view of the lack of quantitative research, practical applicability and weak guidance to engineering practice, this paper introduces Shapley value correction method to redistribute the risk sharing principle of construction contract caused by force majeure. Based on this principle, Shapley value amendment method of contract price adjustment mechanism.

Finally, in the light of the situation of the dismissal caused by the force majeure, this paper analyzes the research on the force majeure caused by contract dismantlement in construction projects, the research on the way of dismissal caused by force majeure and the exemption of liability after the dismissal of the contract.

\section{References}

[1] Zhang Xiaoli .Realization of construction contract price adjustment under the perspective of risk sharing [D] Tianjin: Tianjin University of Technology, 2013.

[2] Zhao Hua. Research on the mechanism of risk sharing on the performance of project 
management [D]. Tianjin: Tianjin University, 2012.

[3] Wan Lifeng, Yin Yi-lin. International Engineering Contract Price Adjustment and Risk Analysis under FIDIC [J]. International Economic Cooperation, 2010 (4): 57-61.

[4] Guo Kaiyin. Project cost management system. [D]. Tianjin: Tianjin University of Technology, 2011.

[5] WEI Xuecheng, LI Wentao. Research on Benefit Allocation in Supply Chain Alliance Based on Improved Shapley Value [J]. Statistics and Decision, 2010 (23): 53-55.

[6] Hu Li, Zhang Weiguo, Ye Xiaosu. Study on Profit Distribution Model of PPP Project Based on SHAPELY Amendment [J] .Journal of Management Science, 2011, 25 (2): 149-154.

[7] Liu Jinming. Research on the flexible provisions of engineering change under the perspective of improving contract performance [D] Tianjin: Tianjin University of Technology, 2017. 